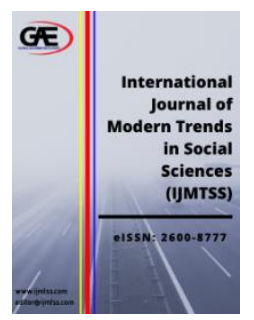

\author{
INTERNATIONAL JOURNAL OF \\ MODERN TRENDS IN \\ SOCIAL SCIENCES \\ (IJMTSS) \\ wWw.ijmtss.com
}

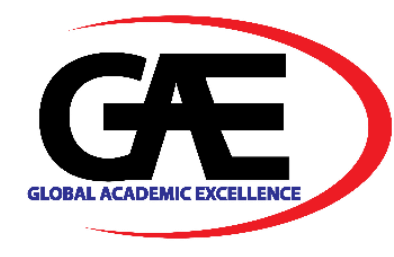

\title{
THE INFLUENCE OF SOCIAL MEDIA USAGE ON QUALITY TIME SPENT WITH FAMILY AMONG IIUM STUDENTS
}

\author{
Siti Hajar Mohd Badrol ${ }^{1 *}$, Saodah Wok ${ }^{2}$ \\ 1 International Islamic University of Malaysia \\ Email: hajarbadrol@gmail.com \\ 2 International Islamic University of Malaysia \\ Email:wsaodah@iium.edu.my \\ Corresponding Author
}

\section{Article Info:}

\section{Article history:}

Received date:27.09.2020

Revised date: 13.10 .2020

Accepted date: 20.10.2020

Published date: 03.12.2020

\section{To cite this document:}

Badrol, S. H. M., \& Wok, S. (2020). The Influence of Social Media Usage on Quality Time Spent with Family among IIUM Students. International Journal of Modern Trends in Social Sciences, 3 (14), 01-20.

\section{DOI: $10.35631 /$ IJMTSS.314001}

This work is licensed under CC BY 4.0

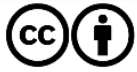

\begin{abstract}
:
This study was conducted to determine social media usage and its influence on the quality time spent with family among the students of the International Islamic University of Malaysia (IIUM). The objectives of the study are to determine: (a) the exposure to social media use; (b) the level of perception, attitude, and behavior towards social media use, and the quality time spent with family; and (c) the relationships of perception, attitude, and behaviour towards social media use with the quality time spent with family. Time displacement theory was used to explain the relationship between the variables. The quantitative research design was employed using a network sampling survey method, with a questionnaire as a tool for data collection. A total of 210 respondents participated in this study. The findings of the study revealed that WhatsApp is the most frequently used social media platform, followed by YouTube, E-mail, Instagram, Facebook, and Telegram. The levels of perception, attitude, and behavior towards social media usage and the quality of time spent with family are high and significant. Perception, attitude, and behavior were found to show a significant positive correlation with social media usage and the quality time spent with family. Thus, this study suggests that students should allocate the time they spend on social media for their families.
\end{abstract}

Keywords:

Attitude, Behavior, Family Quality Time, Perception, Social Media 


\section{Introduction}

\section{Background of the Study}

Nowadays, more than half of the world population are using social media in their daily life. The Star on May 3, 2019, reported that Malaysia had witnessed an influx of social media usage with $96.5 \%$ of individuals using the Internet to access their social media accounts in 2018. According to Malaysia's Chief Statistician, Datuk Seri Dr. Mohd Uzir Mahidin (Bernama, 2019), the increase is in line with the increasingly busy lifestyle of individuals in Malaysia. This increase also impacts the interaction and communication among family members as social media has become the main choice of medium for communication.

Communication is one of the most vital parts in building the family institution in ensuring strong and healthy relationships and bonding among family members. Nowadays, social media plays a vital role in communication and it has become a necessity in life and personal interactions (Edge, 2017). According to New Straits Times (May 3, 2017), there were 14 million Facebook users in Malaysia in 2019 and Malaysians spent an average of 2.8 hours a day and 7.2 hours a week streaming online videos (Kushairi, 2017).

The existence of social media has substantially changed the way people communicate with their family members over the years. Ten years back, people were using short message service (SMS), direct messages, and calls to communicate with family members but today the situation has changed, and families all around the world are widely and commonly using social media as a form of communication.

\section{Problem Statement}

Malaysia has recorded a steep increase in the percentage of active social media users from 62 percent in 2016 to 81 percent as of January 2020 (Müller, 2020). Datuk Dr. Wan Azizah Wan Ismail, the former Deputy Minister of Malaysia said that the use of technology would encourage people to stop relying on real-world communication, thus affecting the relationships among individuals and families. She was concerned about the obsession of society and their high dependence on technology and social media that even children as young as two years' old were exposed to gadgets like smartphones. She also said that the misuse of technology has put people at the forefront of gadgets to access information and only interact in cyberspace, thus making them ignore the surrounding people and the physical world (Rosly, 2019).

The increase in the usage of social media by families resulted from technological development. This study, therefore, seeks to explore how social media usage influences the quality time spent in the family. Will social media usage displace the quality time with family? Given the problems, this study focuses on examining the influence of social media usage on the quality time spent with family among International Islamic University Malaysia (IIUM) students.

\section{Research Objectives}

The objectives of the study are:

1) To find out the degree of exposure to social media usage among IIUM students;

2) To determine the level of perception, attitude, and behavior towards social media usage among IIUM students;

3) To determine the level of quality time spent with family among IIUM students; and 
4) To analyze the relationships of perception, attitude, and behavior towards social media usage with the quality time spent with family among IIUM students.

\section{Significance of the Study}

This research is expected to be useful to students of higher education institutions, parents, and the Ministry of Women, Family and Community Development. This study taps on the understanding of how social media usage in daily life influences students' quality time spent with their family members. The time displacement theory is used to explain how social media displaces quality time with family, which can help students to allocate more time with their family because the displacement theory depicts that the time used for a particular activity cannot be used for another activity simultaneously without losing the available time.

The findings of this study are expected to assist the Ministry of Women, Family and Community Development in determining the influence of social media usage on the lives of youths, especially college students, on their quality time spent with family members. Further, the Ministry might be able to use the findings of this study to formulate policies that will positively influence the lives of youths such as by blocking and limiting the access to social media for teenagers starting from 12 a.m. to 6 a.m. as what is being done in Japan and Korea. This study is also expected to extend the understanding of family communication. By looking at family communication as a new dimension, the findings from this paper will help address a major deficit in the current literature on the influence of social media usage on the quality time spent with family through students' experience. It can help students and parents to understand and be aware of the influences of social media usage on their quality time spent with family members.

This study is also expected to be useful to the time displacement theory as this research examines the influence of social media usage on quality time spent with family, which explains that as people concentrate on one issue, they will have less time to focus on anything else. Thus, this study will help students to understand how social media usage can displace the quality time that they spend with family in their daily life.

\section{Literature Review}

\section{Social Media}

Social media is known as an Internet-based site where people can communicate in a two-way manner over the World Wide Web (www), which has brought impacts on individual, organizational, and societal stages (Lucas Jr, Agarwal, Clemons, El Sawy, \& Weber, 2013). Meanwhile, Boyd and Ellison (2008) defined social media as a medium for generating profiles, making relationships visible and traverse.

Some of the most popular social media websites around the world with over 100 million registered users are Facebook, YouTube, WeChat, Instagram, Weibo, Twitter, Telegram, LinkedIn, WhatsApp, LINE, and Snapchat. Further, Malaysian Chief Statistician stated that Facebook, Instagram, Twitter, and Whats App are the main choices of social media in Malaysia (Bernama, 2019). Siew, Nor Syamimi, Nor Hairunnisa, and Nur Ain (2017) reported that students prefer to use smartphones and laptops the most as these devices can fulfil their needs. Besides, they can also access their social media every day to fulfill their personal, communication, and interaction needs (Aghaee, 2010). 


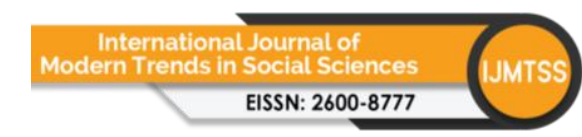

Volume 3 Issue 14 (December 2020) PP. 01-20

DOI 10.35631/IJMTSS.314001

Many students and youths in the current age are digital natives. Thus, over 80 percent of youths around the world spend a lot of time on the Internet. This happens as the Internet is incorporated and exposed into their lives from a very young age. Besides, the modern generation of children and teenagers are the first community and group to use the Internet on a big scale and among the first to face issues associated with excessive usage of the Internet (Subrahmanyam, Greenfield, \& Tynes, 2004).

Social media is a bridge that connects people with their family members that stay separately from each other, and it is a great tool for bridging the geographic distance among them (Le Moignan, 2017). Watt (2016) stated that social media usage in a family is crucial in maintaining the social connection and bonding among family members, as nowadays people are living in a digital world. However, Huisman, Edwards, and Catapano (2012) indicated that the connectivity in a family, which is made possible by mobile apps and social media, needs to be managed in certain times, places, and occasions. The usage of social media and the Internet as the medium of communication needs to be controlled constantly. A lack of control and coordination over the usage of social media and mobile devices in the family by parents will result in negative outcomes to the family's relationships. Thus, quality family time plays a crucial role in strengthening the bonding and connection among family members.

\section{Quality Family Time}

Daly (2001) defined quality family time as any time a family has to spend together, such as eating dinner, playing games, hiking, making crafts, or going on vacations. Thus, not all family time is considered quality simply because family members spend time together. Family time will be productive and useful when everyone can concentrate on one another, relaxing and enjoying each other's company. For him, quality family time is togetherness, which requires the family's attention while focusing on each other (Daly, 2001).

However, Christensen (2002) opined that quality time spent with family focuses on the time that is shared by all family members, consisting mainly of leisure activities and events that focus on the needs and interests of children, such as outdoor activities. Quality time is a precious and meaningful time to spend with important people such as family members and friends. Families are still seen as basic units of society and are the oldest and most significant of all human institutions (Zabriskie \& McCormick, 2001). Thus, quality time undeniably is important in the family institution and it has a relationship with perception, attitude, and behavior towards social media usage.

\section{Quality Time Spent with Family and Perception of Social Media Usage}

Most of the students in this modern era use social media to connect and interact with their family members through text message applications. Lanigan (2009) indicated that technology provides significant power to generate innovative thoughts as well as serving as a mechanism that changes the way family members communicate with each other. He stated that technology could give positive outcomes and effects to a family relationship if it is used in the right way, and it can enhance the relationship further in terms of family cohesion, adaptability, and open communication.

In line with the growth of technology, many family institutions began to adopt social media and social networking sites as their medium to connect with each other. This happened due to the perception that family members would react positively towards social media usage in family communication. Social media allows family members to remain in contact and plan in 


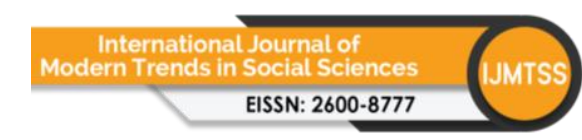

Volume 3 Issue 14 (December 2020) PP. 01-20

DOI 10.35631/IJMTSS.314001

real time, guarantees the safety of children as they can communicate in times of emergency, strengthens family connections, empowers interactions between parents and children, and also promotes and supports discussions between family members (Coyne et al., 2014). This indicates that social media can help families spend quality time together. Besides, the attitude towards social media usage also has a relationship with the quality time spent with family.

\section{Quality Time Spent with Family and Attitude towards Social Media Usage}

Attitude is defined as a psychological tendency, which is shown in the evaluation of certain entities with some degree of favor or disfavor (Eagly \& Chaiken, 1993). For example, a student has a positive attitude towards social media usage. The student will probably want to use social media in many situations including communicating with their family. The student who has a positive attitude towards social media usage might suggest that social media application to other students as well. On the other hand, if a student has a negative attitude towards social media usage, the student may not choose to use it often. The attitude of an individual towards a person or thing affects that individual's behavior towards that person or thing, and such attitude can also be improved and changed.

Abraham (2020) in his study on the attitude of adolescents towards social media found that 64 percent of students firmly agreed that social media helps to sustain their relationship with their family. It also helps to widen the circle of connections in which people are unable to meet faceto-face. The study also found that more than half of the students disagreed with the statement that social media takes them far away from the person who is staying close to them. Zhou, Zhang, Yang, and Wang (2017) discovered that families and friends have used social media to remain connected when they are far apart from each other. This connection inspires a healthy family relationship and helps adolescents to remain close to their family members and peers. Meanwhile, behavior towards social media usage has also shown some relationship with the quality time spent with family.

\section{Quality Time Spent with Family and Behaviour towards Social Media Usage}

Social media allows families to remain connected anytime they need each other. In a 2008 study published by Pew Research Center's Internet \& American Life Project, it was found that Internet access and mobile devices had a positive impact on the quality of communication with family members. The behavior in using the Internet and social media helped families to balance the increased stress of modern life by allowing them to communicate and stay in touch with family members when they were physically apart.

Anderson and Jiang (2020) stated that 81 percent of the teenagers between the ages of 13 and 17 found that social media helped them feel more engaged with others in their lives and 68 percent said that it helped them feel supported especially in difficult times. According to a 2015 report by Pew Research Center, the age group of 65 and older was one of the fastest-growing population groups on social media platforms, with the usage of social media increasing from 2 percent of seniors in 2008 to 35 percent in 2015. Besides that, they also expressed that they were feeling better because of the online social interaction and contact with family (Perrin, 2020). This finding indicates that the behavior of individuals in using social media is associated positively with the quality time spent with family.

This study uses the time displacement theory to explain the influence of social media usage on the quality time spent with family. 


\section{Time Displacement Theory}

Maxwell McCombs introduced and developed the displacement theory in 1992. This theory is based on the amount of time that individuals spend on their daily communication activities as people have specific and limited time available for communication. Thus, every time a new technology is introduced and attracts consumers, there will be less time spent with old technologies or communicating in general (Qi, Shen, \& Dou, 2013).

Further, this theory describes how individuals have a limited time, attention, and participation in communication activities in their life. Thus, every time a new technology in communication is introduced, the participation time in one communication medium removes the others. Therefore, people will have less time for other communication activities as they are focusing more on the new technology, and this new technology also limits their participation time in other activities (Qi et al., 2013). Thus, technologies are accountable for the decrease in common activities in society or families such as in- and out-of-home socializing, personal care, and the time spent with family. The higher the time a person spends on an activity, the more sacrifices that person will have to make on spending time on other activities (Neuman, 1991). For example, when a person spends more time on the Internet, that person will spend less time on other media technologies and other activities such as watching television and communicating with each other in general.

\section{Conceptual Framework}

Based on the literature and the theoretical framework, the conceptual framework is presented in Figure 1.

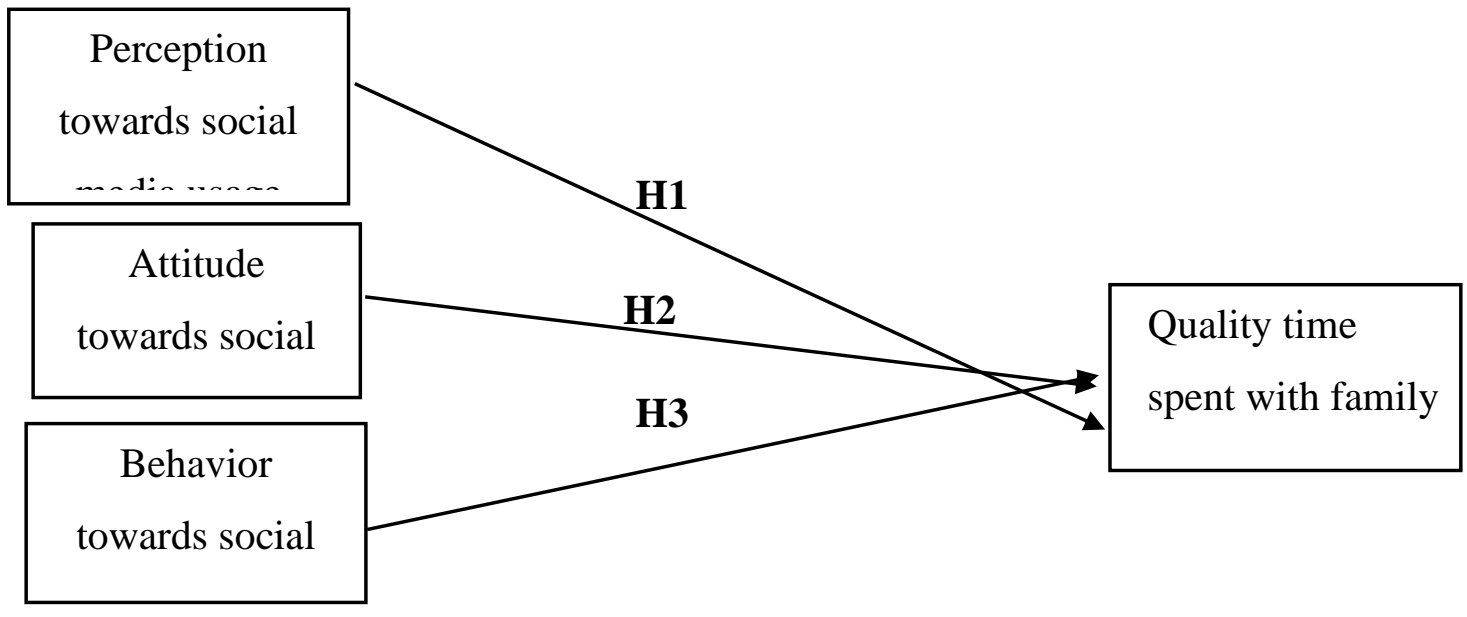

Figure 1: Conceptual Framework on The Influence of Social Media Usage on The Quality Time Spent with Family

\section{Hypotheses of the Study}

Based on the literature and the conceptual framework, the hypotheses of this study are postulated as follows:

H1: There is a positive relationship between the perception towards social media usage and the quality time spent with family. 
$\mathrm{H} 2$ : There is a positive relationship between the attitude towards social media usage and the quality time spent with family.

H3: There is a positive relationship between the behavior towards social media usage and the quality time spent with family.

\section{Methodology}

\section{Research Design}

This study employed quantitative research design. According to Creswell (2014), the quantitative research design is an examination technique which produces numerical data and is expected to discover causal connections between two or more variables. A survey was used as the method for gathering data. A quantitative survey was distributed to International Islamic University Malaysia (IIUM) students through Google Forms, as this study was conducted at the IIUM campus in Gombak which was chosen as the locality of this study. The IIUM Gombak campus has over 30,000 students with seven faculties or known as "kulliyyah" and this university provides students with an Internet connection, which enables students to stay connected online at all times.

\section{Population and Sampling Procedure}

The population of this study consisted of IIUM undergraduate and postgraduate students at the university's Gombak campus. The definition of population in statistics is a large group of people that are selected for a research study and from there, a small sample size is drawn for them to participate in the research (Kenton, 2019). IIUM students were chosen as the population of this study because this study is about social media usage and students are one of the main users of social media. Data collection took place from June 1 to June 20, 2020. The sample of 210 students was obtained through the networking sampling procedure. This sampling enabled the researchers to gain access to individuals who live outside campus using online forms as students were not allowed to be in the campus due to the movement control order (MCO) during the COVID-19 pandemic period.

\section{Instrument and Measurement}

An online survey questionnaire was used in this study and it was divided into six sections to get the desired information from the students. Section 1 is for collecting information on the personal data and demographics of the respondents. Sections 2 to 5 consisted of selfconstructed questions, whereas section 6 was adapted from Ellington (2011). The questions in section 2 elicited responses from the respondents on their exposure to social media use (16 items). The questions tried to elucidate the frequency of using WhatsApp, Telegram, and Facebook. Section 3 covered the students' perception of social media usage (10 items), for instance, "I think using social media to connect with my family is useful." Section 4 aimed to determine the students' attitude towards social media usage (10 items), for example, "I love using social media to communicate with my family." Section 5 is about the students' behavior towards social media usage (10 items), for instance, "I keep myself informed about my family through social media." Lastly, Section 6 is on the quality time spent with family (23 items). An example of the items is "My family members openly express affection." This study featured sections 2, 3, 4, and 5 as the independent variables and section 6 as the dependent variable.

The frequency of using social media and the quality time spent with family were measured using a 5-point Likert-like scale, where $1=$ never, $2=$ rarely, $3=$ sometimes, $4=$ often, and 5 $=$ always. Perception, attitude, and behavior were also measured using a 5-point Likert scale, 
where $1=$ strongly disagree, $2=$ disagree, $3=$ slightly agree, $4=$ agree, and $5=$ strongly agree . Each variable was computed to form an overall mean score with a minimum of 1 and a maximum of 5. Thus, in order to calculate the overall percentage of an item, the mean for each item was multiplied by 20 , which is equivalent to $100 \%$ based on the 5 -point scale.

\section{Validity and Reliability}

For this study, only the face validity was considered where the developed items were checked by an expert on measurement and on family communication. A pilot study $(N=30)$ was conducted to measure the reliability of the instrument. An internal reliability test was conducted using Cronbach's alpha. The collected data from the pilot study showed that four of the five variables are reliable as the values exceeded the minimum Cronbach's alpha value of 0.70 , thus indicating the reliability of the variables. Table 1 presents the Cronbach's alpha values of the variables, namely the types of social media used $(\alpha=.637)$, perception towards social media usage $(\alpha=.942)$, attitude towards social media usage $(\alpha=.939)$, behavior towards social media usage $(\alpha=.938)$, and lastly, the quality time spent with family $(\alpha=.951)$. Based on the pilot study results, the variables are strong and reliable enough to be used in the actual study except for the types of social media used. According to Wimmer and Dominick (2014), Cronbach's alpha helps to test the consistency of the answers given by the respondents based on the measured items. Based on the actual study results, the types of social media used $(\alpha=.531)$ is acceptable, and the perception towards social media usage $(\alpha=.922)$, attitude towards social media usage $(\alpha=.913)$, behavior towards social media usage $(\alpha=.917)$, and the quality time spent with family $(\alpha=.952)$ are highly reliable.

Table 1: Reliability Values for Selected Variables

\begin{tabular}{|c|c|c|c|c|}
\hline \multirow[t]{2}{*}{ Section } & \multirow[t]{2}{*}{ Variable } & \multirow{2}{*}{$\begin{array}{l}\text { No. of } \\
\text { Items }\end{array}$} & \multicolumn{2}{|c|}{ Cronbach's alpha } \\
\hline & & & $\begin{array}{l}\text { Pilot Study } \\
\quad(N=30)\end{array}$ & $\begin{array}{l}\text { Actual Study } \\
\qquad(N=210)\end{array}$ \\
\hline 2 & $\begin{array}{l}\text { Types of social } \\
\text { media used }\end{array}$ & 10 & .637 & .531 \\
\hline 3 & $\begin{array}{l}\text { Perception towards } \\
\text { social media usage }\end{array}$ & 10 & .942 & .922 \\
\hline 4 & $\begin{array}{l}\text { Attitude towards } \\
\text { social media usage }\end{array}$ & 10 & .939 & .913 \\
\hline 5 & $\begin{array}{l}\text { Behavior towards } \\
\text { social media usage }\end{array}$ & 10 & .938 & .917 \\
\hline 6 & $\begin{array}{l}\text { Quality time spent } \\
\text { with family }\end{array}$ & 10 & .951 & .952 \\
\hline
\end{tabular}

\section{Data Analysis}

The Statistical Package for the Social Sciences (SPSS) version 22.0 was used to analyze the data obtained from the respondents in order to answer the objectives and to test the hypotheses of the study. Descriptive and inferential statistical analyses were used in this study. For the descriptive statistics, frequencies, percentages, means, and standard deviations were used. Meanwhile, for the inferential analysis, the one-sample $t$-test and bivariate correlation were performed. The one-sample $t$-test was used to achieve the research objective, which is to find out the level of exposure, perception, attitude, and behavior towards social media usage and 
the level of quality time spent with family among IIUM students. Meanwhile, hypotheses 1, 2, and 3 were tested using correlation analysis.

\section{Findings}

\section{Demographic Statistics of the Respondents}

From a total of 210 respondents (Table 2), it was found that the majority of them $(85.7 \%$ ) are female students while the rest are male (14.3\%). Almost two-thirds of the respondents $(63.8 \%)$ are adolescents aged between 21 and 25 years old, followed by young adults $(28.6 \%)$ and finally teenagers (7.6\%). As for their level of education, slightly more than two-thirds of the respondents $(67.6 \%)$ are pursuing their bachelor degree, followed by those attending postgraduate programs $(22.4 \%)$ while the rest $(10.0 \%)$ are at their foundation level. More than three-quarters of the respondents $(78.1 \%)$ are Malaysian students, while the rest are international students.

Table 2: Demographic Characteristics of the Respondents

\begin{tabular}{llcc}
\hline $\begin{array}{l}\text { Demographic } \\
\text { characteristic }\end{array}$ & \multicolumn{1}{c}{ Category } & Frequency & Percentage \\
\hline Gender & Male & 30 & 14.3 \\
& Female & 180 & 85.7 \\
\hline \multirow{2}{*}{ Tge (years old) } & Less than 20 & $\mathbf{2 1 0}$ & $\mathbf{1 0 0 . 0}$ \\
& $21-25$ & 16 & 7.6 \\
& $26-30$ & 134 & 63.8 \\
& $31-35$ & 42 & 20.0 \\
& $36-40$ & 11 & 5.2 \\
& 41 and above & 5 & 2.4 \\
& Total & 2 & 1.0 \\
\hline Level of education & Foundation & $\mathbf{2 1 0}$ & $\mathbf{1 0 0 . 0}$ \\
& Degree & 21 & 10.0 \\
& Master & 142 & 67.6 \\
& PhD & 42 & 20.0 \\
& Total & 5 & 2.4 \\
\hline Nationality & Malaysian & $\mathbf{2 1 0}$ & $\mathbf{1 0 0 . 0}$ \\
\hline & Tnternational & 164 & 78.1 \\
& Total & $\mathbf{2 1 0}$ & 21.9 \\
\hline
\end{tabular}

\section{Types of Gadgets to Access Social Media}

The types of gadgets used to access their social media accounts are mainly laptops and smartphones (Table 3). However, the respondents preferred using a smartphone (97.6\%) rather than a laptop (2.4\%) to access their social media accounts. 
Table 3: Types of Gadgets to Access Social Media

\begin{tabular}{|c|c|c|}
\hline $\begin{array}{l}\text { Types of Gadgets } \\
\text { to Access Social } \\
\text { Media }\end{array}$ & Frequency & Percentage \\
\hline Laptop & 5 & 2.4 \\
\hline Smartphone & 205 & 97.6 \\
\hline Total & 210 & 100.0 \\
\hline
\end{tabular}

\section{Types of Social Media Used}

Table 4 shows the types of social media used by IIUM students to access their social media accounts. It was found that almost all of the respondents used WhatsApp (95.6\%), and the majority of them also used YouTube (82.3\%). More than three-quarters of them used e-mail $(79.4 \%)$ and Instagram (77.0\%) to access their social media accounts. Many preferred using Facebook (69.0\%), while some of them used Telegram (61.3\%) and Twitter (56.2\%). However, Messenger (48.4\%), Snapchat (31.1\%), and TikTok (29.4\%) were found to be underutilized by the respondents.

Overall, the result for the types of social media used is positive $(63.0 \%)$ and significant $(t=$ $4.388, p=.000)$ with a mean value of $3.149(S D=0.492)$. This result indicates that the level of usage and exposure to social media is high for the selected types of social media. Hence, the first research objective is achieved.

Table 4: Types of Social Media Used

\begin{tabular}{llcccrcc}
\hline No. & Types of Social Media Used $(\boldsymbol{N = \mathbf { 2 1 0 } )}$ & $\boldsymbol{M}^{*}$ & $\boldsymbol{S} \boldsymbol{D}$ & $\boldsymbol{\%}$ & \multicolumn{1}{c}{$\boldsymbol{t}^{* *}$} & $\boldsymbol{d} \boldsymbol{f}$ & $\boldsymbol{\rho}$ \\
\hline 1 & WhatsApp & 4.781 & 0.498 & 95.6 & 51.779 & 209 & .000 \\
2 & YouTube & 4.114 & 0.873 & 82.3 & 18.498 & 209 & .000 \\
3 & Email & 3.971 & 0.907 & 79.4 & 15.526 & 209 & .000 \\
4 & Instagram & 3.848 & 1.224 & 77.0 & 10.035 & 209 & .000 \\
5 & Facebook & 3.452 & 1.264 & 69.0 & 5.186 & 209 & .000 \\
6 & Telegram & 3.067 & 1.220 & 61.3 & 0.792 & 209 & .429 \\
7 & Twitter & 2.810 & 1.575 & 56.2 & -1.753 & 209 & .081 \\
8 & & 2.419 & & & & & \\
& Messenger & & 1.314 & 48.4 & -6.405 & 209 & .000 \\
9 & Snapchat & 1.557 & 0.988 & 31.1 & -21.173 & 209 & .000 \\
10 & TikTok & 1.471 & 1.031 & 29.4 & -21.477 & 209 & .000 \\
& Overall Types of Social Media Used & $\mathbf{3 . 1 4 9}$ & $\mathbf{0 . 4 9 2}$ & $\mathbf{6 3 . 0}$ & $\mathbf{4 . 3 8 8}$ & $\mathbf{2 0 9}$ & $\mathbf{. 0 0 0}$ \\
\hline
\end{tabular}

* On a 5-point scale, where $1=$ never $(1-20 \%), 2=$ rarely $(21-40 \%), 3=$ sometimes $(41-60 \%), 4=$ often $(61-$ $80 \%)$, and $5=$ always $(81-100 \%)$.

$* *$ Test value $=3$

\section{Intensity of Social Media Usage}

Unfortunately, students tend to spend less time communicating with their family (Table 5). About $22.9 \%$ of the respondents spent $31-45$ minutes, another $21.0 \%$ spent $46-60$ minutes, and $19.3 \%$ spent 61 minutes and above per sitting on using social media. Only 5.8\% used social media less than 15 minutes per sitting. On the contrary, about one-third of the respondents (31.0\%) reported spending less than 15 minutes per sitting on social media to communicate with family, followed by another one-third of them (33.3\%) spending 16-30 minutes per sitting, and $15.7 \%$ of the respondents spending either $31-45$ minutes or $46-60$ minutes per sitting on social media to communicate with their family. Only $4.3 \%$ used more than one hour 
per sitting on social media to communicate with their family. Overall, the percentage of those spending time communicating with their family decreases as the time allocation increases. For the frequency of using social media per day, it was found that two-thirds of the respondents $(67.6 \%)$ accessed their social media more than five times per day. Many of them $(14.3 \%)$ accessed their social media four times per week and another $14.3 \%$ accessed it thrice a day. Only $3.3 \%$ of them accessed social media twice a day.

In terms of the frequency of accessing social media per week, almost all of the respondents (91.3\%) used it every day. Besides, the respondents admitted to the importance of social media in family communication. Overall, the percentage of respondents increases as the level of importance increases. The results show that more than two-fifths of them (43.3\%) agreed that social media is very important while $37.1 \%$ of them rated it as important for family communication. Only $5.3 \%$ of the respondents felt that social media is not important for family communication.

Table 5: Intensity of Social Media Usage

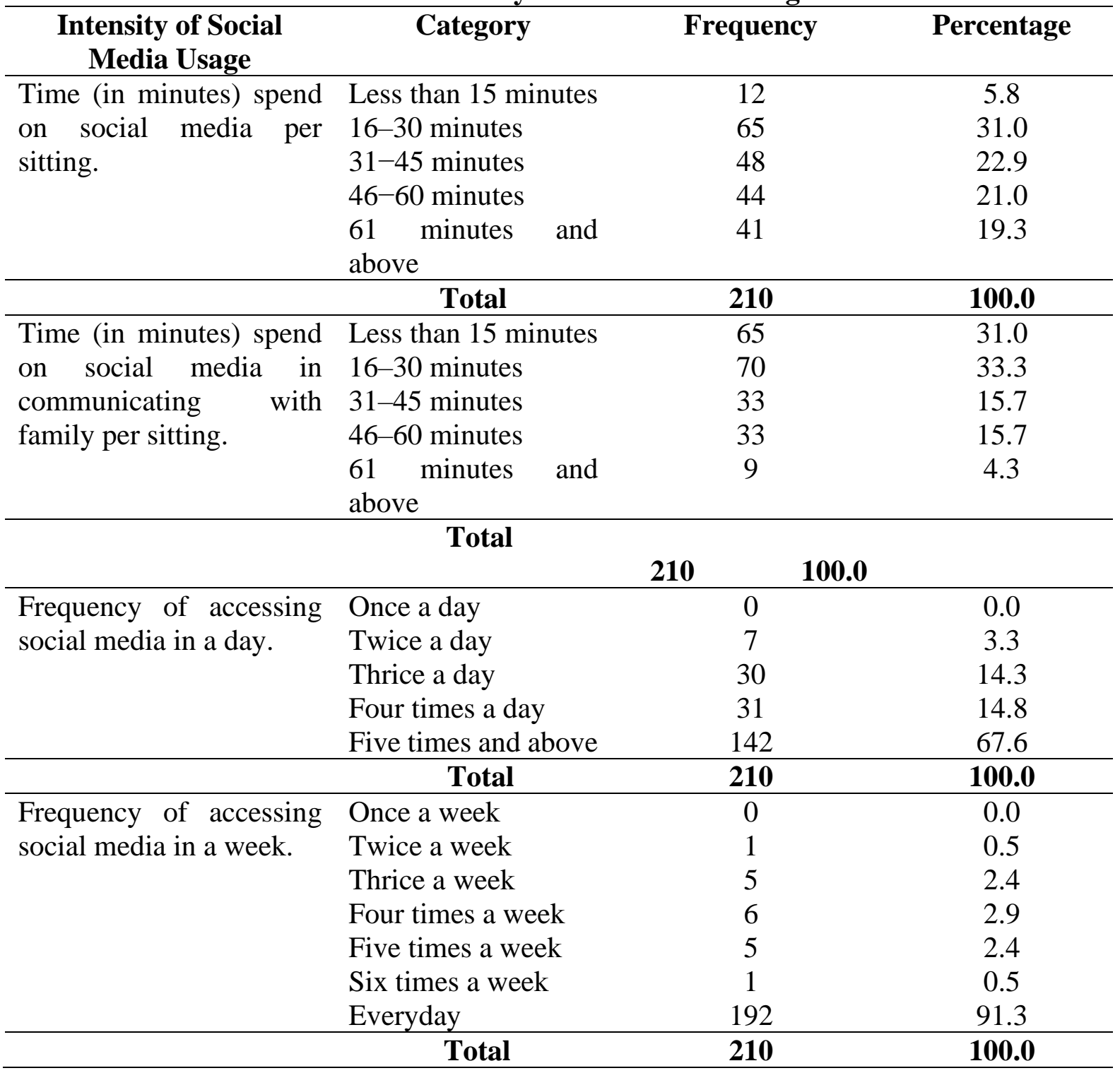




\begin{tabular}{llcc}
\hline Importance of the use of & Not important at all & 2 & 1.0 \\
social media in family & Not important & 9 & 4.3 \\
communication. & Slightly important & 30 & 14.3 \\
& Important & 78 & 37.1 \\
& Very important & 91 & 43.3 \\
\hline & Total & $\mathbf{2 1 0}$ & $\mathbf{1 0 0 . 0}$ \\
\hline
\end{tabular}

\section{Perception towards Social Media Usage in Family Communication}

Table 6 shows the results of one-sample $t$-test for the respondents' level of perception towards social media usage. All items on the perception towards social media usage recorded significant response rates. The majority of the respondents thought that using social media to connect with their family is useful (86.6\%) and that it is easy to communicate with their family on social media $(85.8 \%)$. Further, they thought that social media provides useful information on family daily activities (81.5\%), strengthens the bonding among family members (78.5\%), gives benefits in communicating with family $(78.4 \%)$, and increases social interaction with family (75.8\%). Also, $71.8 \%$ admitted that they would be willing to use social media as part of their daily communication medium with family. Besides, the respondents thought that social media enhances their communication skill with family (69.9\%), provides accurate and trustworthy information to them and their family (69.0\%), and encourages them to know their family better $(67.5 \%)$. Generally, the respondents had a positive perception of social media in family communication $(76 \%)$ with an overall mean of $3.824(S D=0.796 ; t=14.992, p=.000)$. The result confirms that the level of perception towards social media usage in family communication is high and hence, the second research objective on perception is achieved.

Table 6: Perception towards Social Media Usage in Family Communication

\begin{tabular}{|c|c|c|c|c|c|c|c|}
\hline No. & $\begin{array}{l}\text { Perception towards Social Media } \\
\text { Usage in Family Communication }(N= \\
\text { 210) }\end{array}$ & $M^{*}$ & $S D$ & $\%$ & $t^{* *}$ & $d f$ & $\rho$ \\
\hline 1 & $\begin{array}{l}\text { I think using social media to connect with } \\
\text { my family is useful. }\end{array}$ & 4.329 & 0.825 & 86.6 & 23.330 & 209 & .000 \\
\hline 2 & $\begin{array}{l}\text { I think it is easy to communicate with my } \\
\text { family by using social media. }\end{array}$ & 4.291 & 0.884 & 85.8 & 21.158 & 209 & .000 \\
\hline 3 & $\begin{array}{l}\text { I think using social media provides me } \\
\text { with useful information on my family } \\
\text { daily activities. }\end{array}$ & 4.076 & 0.965 & 81.5 & 16.155 & 209 & .000 \\
\hline 4 & $\begin{array}{l}\text { I think using social media strengthens the } \\
\text { bonding among my family members. }\end{array}$ & 3.924 & 0.975 & 78.5 & 13.727 & 209 & .000 \\
\hline 5 & $\begin{array}{l}\text { I believe using social media gives me } \\
\text { benefits in communicating with my } \\
\text { family. }\end{array}$ & 3.919 & 1.057 & 78.4 & 12.597 & 209 & .000 \\
\hline 6 & $\begin{array}{l}\text { I believe that using social media increases } \\
\text { my social interaction with my family. }\end{array}$ & 3.791 & 1.104 & 75.8 & 10.375 & 209 & .000 \\
\hline 7 & $\begin{array}{l}\text { I think I am willing to use social media } \\
\text { sites as part of my daily communication } \\
\text { medium with my family. }\end{array}$ & 3.591 & 1.192 & 71.8 & 7.181 & 209 & .000 \\
\hline 8 & $\begin{array}{l}\text { I believe that using social media enhances } \\
\text { my communication skill with my family. }\end{array}$ & 3.495 & 1.095 & 69.9 & 6.555 & 209 & .000 \\
\hline
\end{tabular}


9 I think social media provides accurate and

$\begin{array}{llllll}3.448 & 1.067 & 69.0 & 6.080 & 209 & .000\end{array}$

trustworthy information to me and my

family.

10 I think using social media encourages me $\begin{array}{llllll}3.376 & 1.205 & 67.5 & 4.526 & 209 & .000\end{array}$

to know my family better.

$\begin{array}{lllllllll}\text { Overall Perception towards } & \text { Social } & 3.824 & 0.796 & 76.5 & 14.992 & 209 & .000\end{array}$ Media Use in Family Communication

* On a 5-point scale, where $1=$ strongly disagree (1-20\%), $2=$ disagree (21-40\%), $3=$ slightly agree $(41-60 \%)$, $4=$ agree $(61-80 \%)$, and $5=$ strongly agree $(81-100 \%)$.

** Test value $=3$

\section{Attitude towards Social Media Usage in Family Communication}

Table 7 presents a one-sample $t$-test for the students' attitude towards social media use with regards to family communication. The results indicate that more than three-quarters of the respondents (78.9\%) felt that it is important to be able to access social media anytime and anywhere to remain connected with their family, with a mean value of $3.943(S D=1.047)$. The respondents also agreed that using social media makes them connected with family $(77.5 \%)$, they love using social media to communicate with family $(74.8 \%)$, social media brings their relationships with their family closer $(73.0 \%)$, they feel that all family members should have a social media account to communicate $(72.5 \%)$, they become anxious when the Internet is not available to access social media for family communication $(68.5 \%)$, they prefer using social media during their free time for family sake $(67.8 \%)$, they get more things accomplished with their family using social media (66.4\%), and they like to spread awareness among family members about the importance of using social media (64.7\%). However, item 10 recorded a negative and insignificant $t$-value $(t=-0.982, p=0.327)$, which means that the respondents did not agree that social media will provide solutions to many of their family problems. The overall result for attitude shows that about seven in ten respondents $(70.2 \%)$ scored highly on the attitude towards social media usage with a mean value of $3.511(S D=0.835 ; t=8.874, p=$ .000 ), indicating a high and positive level of attitude towards social media use. Hence, the second research objective on attitude is achieved.

Table 7: Attitude towards Social Media Usage in Family Communication

\begin{tabular}{|c|c|c|c|c|c|c|c|}
\hline No. & $\begin{array}{l}\text { Attitude towards Social Media Usage } \\
\text { in Family Communication }(N=\mathbf{2 1 0})\end{array}$ & $M^{*}$ & $S D$ & $\%$ & $t * *$ & $d f$ & $\rho$ \\
\hline 1 & $\begin{array}{l}\text { I feel it is important to be able to access } \\
\text { social media anytime and anywhere to } \\
\text { remain connected with my family. }\end{array}$ & 3.943 & 1.047 & 78.9 & 13.044 & 209 & .000 \\
\hline 2 & $\begin{array}{l}\text { I agree that using social media does } \\
\text { connect me and my family. }\end{array}$ & 3.876 & 1.014 & 77.5 & 12.525 & 209 & .000 \\
\hline 3 & $\begin{array}{l}\text { I love using social media to communicate } \\
\text { with my family. }\end{array}$ & 3.738 & 1.073 & 74.8 & 9.969 & 209 & .000 \\
\hline 4 & $\begin{array}{l}\text { I feel that social media makes my } \\
\text { relationships with my family become } \\
\text { closer. }\end{array}$ & 3.652 & 1.071 & 73.0 & 8.829 & 209 & .000 \\
\hline 5 & $\begin{array}{l}\text { I feel that all family members should have } \\
\text { a social media account to communicate } \\
\text { with each other. }\end{array}$ & 3.624 & 1.148 & 72.5 & 7.877 & 209 & .000 \\
\hline
\end{tabular}


6 I get anxious when I don't have the Internet available to access my social media for family communication.

$\begin{array}{cccccc}3.424 & 1.172 & 68.5 & 5.238 & 209 & .000 \\ 3.391 & 1.115 & 67.8 & 5.073 & 209 & .000 \\ 3.319 & 1.140 & 66.4 & 4.056 & 209 & .000 \\ 3.233 & 1.140 & 64.7 & 2.966 & 209 & .003 \\ & & & & & \\ 2.914 & 1.265 & 58.3 & -0.982 & 209 & .327 \\ \mathbf{3 . 5 1 1} & \mathbf{. 8 3 5} & \mathbf{7 0 . 2} & \mathbf{8 . 8 7 4} & \mathbf{2 0 9} & \mathbf{. 0 0 0}\end{array}$
I prefer to use social media in my free time for my family sake.

8 I feel that I get more things accomplished with my family by using social media.

9 I like to spread awareness amongst my family members about the importance of using social media.

10 I agree that social media will provide solutions to many of my family problems.

$\begin{array}{lllllll}\text { Overall Attitude towards Social Media } & 3.511 & .835 & 70.2 & 8.874 & 209 & .000\end{array}$ Use in Family Communication

* On a 5-point scale, where 1 = strongly disagree (1-20\%), $2=$ disagree (21-40\%), $3=$ slightly agree (41-60\%), $4=$ agree $(61-80 \%)$, and $5=$ strongly agree $(81-100 \%)$.

** Test value $=3$

\section{Behavior towards Social Media Usage in Family Communication}

A one-sample $t$-test was performed on the students' level of behavior towards social media usage. The results in Table 8 show that about three-quarters of the respondents (75.9\%) used social media to communicate and interact with family, to keep themselves informed about their family (75.0\%), to gain additional and relevant information about their family $(73.3 \%)$, and to discuss any news and issues with their family (72.2\%). Further, they also used social media to communicate, mobilize, and organize family events $(68.8 \%)$ and to express love to family members $(66.4 \%)$. Talking about their ideas and beliefs with their family $(62.1 \%)$ is positive but not significant. Also, only $58.7 \%$ of the respondents recommended their family to always update their social media and checked the family members' social media for updates about their life (58.7\%), relied on social media in almost all matters related to their family $(54.8 \%)$, and shared problems with their family through social media $(54.3 \%)$. Regardless, the overall mean for behavior shows a high level of behavior towards social media usage in family communication, with a mean of $3.307(S D=0.883 ; t=5.034, p=.000)$. This result implies that even though several items are insignificant and not positively rated, the students still regarded their behavior towards social media usage as high. Hence, the second research objective on behavior is achieved.

Table 8: Behavior towards Social Media Usage in Family Communication

\begin{tabular}{|c|c|c|c|c|c|c|c|}
\hline No. & $\begin{array}{l}\text { Behavior towards Social Media Usage } \\
\text { in Family Communication }(N=\mathbf{2 1 0})\end{array}$ & $M^{*}$ & $S D$ & $\%$ & $t^{* *}$ & $d f$ & $\rho$ \\
\hline 1 & $\begin{array}{l}\text { I use social media for communicating and } \\
\text { interacting with family. }\end{array}$ & 3.795 & 1.017 & 75.9 & 11.331 & 209 & .000 \\
\hline 2 & $\begin{array}{l}\text { I keep myself informed about my family } \\
\text { through social media. }\end{array}$ & 3.748 & 1.062 & 75.0 & 10.204 & 209 & .000 \\
\hline 3 & $\begin{array}{l}\text { I gain additional and relevant information } \\
\text { about my family on social media. }\end{array}$ & 3.667 & 1.009 & 73.3 & 9.577 & 209 & .000 \\
\hline 4 & $\begin{array}{l}\text { I always use social media as the medium } \\
\text { to discuss any news and issues with my } \\
\text { family. }\end{array}$ & 3.610 & 1.058 & 72.2 & 8.348 & 209 & .000 \\
\hline
\end{tabular}


5 I use social media for communicating, mobilizing and organizing family events.

6 I express love to my family members by using social media.

$7 \quad$ I talk about my ideas and beliefs with my family through social media.

8 I recommend my family to always update their social media and check on their social media for updates about my life.

9 I rely on social media in almost all matters related to my family.

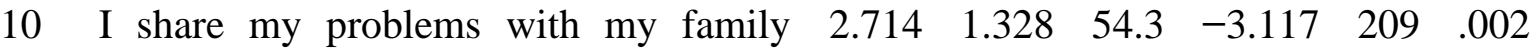
through social media.

$\begin{array}{lllllll}\text { Overall Behavior towards Social Media } & 3.307 & 0.883 & 66.1 & 5.034 & 209 & .000\end{array}$ Use in Family Communication

\footnotetext{
* On a 5-point scale, where $1=$ strongly disagree (1-20\%), $2=$ disagree (21-40\%), $3=$ slightly agree $(41-60 \%)$, $4=$ agree $(61-80 \%)$, and $5=$ strongly agree $(81-100 \%)$.

$* *$ Test value $=3$
}

\section{Quality Time Spent with Family}

Table 9 shows the results of one-sample $t$-test for the quality time spent by respondents with their family. The results indicate that the majority of respondents $(80.5 \%)$ informed that their family members go on vacation together, with a mean of $4.024(S D=1.065)$. The respondents also indicated that they do many of the activities with their family, but their family members hardly go to child-centered places together, with a mean of $2.843(S D=1.237 ; t=-1.841, p=$ $0.000)$ or read books together, with a mean of $2.533(S D=1.137 ; t=-5.947, p=0.000)$, which exhibited negative values. Overall, about seven in ten of respondents $(70.7 \%)$ perceived highly on the quality time spent with family, with a mean value of $3.535(S D=0.775 ; t=10.003, p=$ 0.000), indicating the existence of a high and positive level of quality time spent with family. Hence, the third research objective is achieved.

Table 9: Quality Time Spent with Family

\begin{tabular}{|c|c|c|c|c|c|c|c|}
\hline No. & $\begin{array}{l}\text { Quality Time Spent with family }(N= \\
210)\end{array}$ & $M^{*}$ & $S D$ & $\%$ & $t^{* * *}$ & $d f$ & $\rho$ \\
\hline 1 & $\begin{array}{l}\text { My family members go on vacation } \\
\text { together. }\end{array}$ & 4.024 & 1.065 & 80.5 & 13.936 & 209 & .000 \\
\hline 2 & $\begin{array}{l}\text { My family members go for outings } \\
\text { together. }\end{array}$ & 3.914 & 1.013 & 78.3 & 13.080 & 209 & .000 \\
\hline 3 & My family members eat dinner together. & 3.910 & 1.034 & 78.2 & 12.752 & 209 & .000 \\
\hline 4 & $\begin{array}{l}\text { My family members have a fun talk } \\
\text { session together. }\end{array}$ & 3.905 & 1.063 & 78.1 & 12.336 & 209 & .000 \\
\hline 5 & My family members hang out together. & 3.852 & 1.022 & 77.0 & 12.083 & 209 & .000 \\
\hline 6 & $\begin{array}{l}\text { My family members go to a religious } \\
\text { gathering together. }\end{array}$ & 3.838 & 0.960 & 76.8 & 12.655 & 209 & .000 \\
\hline 7 & $\begin{array}{l}\text { My family members share stories and } \\
\text { experiences with each other. }\end{array}$ & 3.810 & 1.112 & 76.2 & 11.551 & 209 & .000 \\
\hline 8 & $\begin{array}{l}\text { My family members discuss and solve } \\
\text { problems together. }\end{array}$ & 3.767 & 1.006 & 75.3 & 11.042 & 209 & .000 \\
\hline
\end{tabular}


9 My family members go to the store together.

10 My family members eat lunch together.

$\begin{array}{llllll}3.738 & 1.027 & 74.8 & 10.411 & 209 & .000\end{array}$

11 My family members watch television and

3.719

1.045

74.4

$\begin{array}{lll}9.967 & 209 & .000\end{array}$ movie together.

12 My family members clean up after meals

3.686

1.127

$73.7 \quad 8.966$

209.000 together.

13 My family members do household chores

3.667

1.078

$73.3 \quad 8.899$

$209 \quad .000$ together.

14 My family members cook meals together. 3.595

$\begin{array}{lllll}1.070 & 73.1 & 8.820 & 209 & .000\end{array}$

15 My family members eat breakfast together.

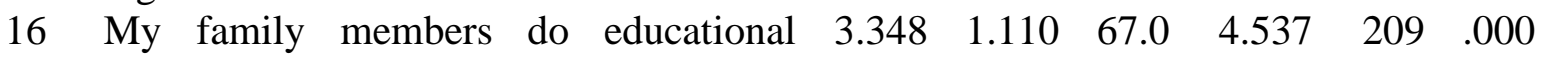
activities together.

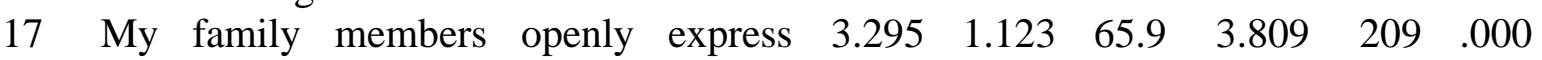
affection.

$\begin{array}{llllllllll}18 & \text { My family members go to the park } & 3.262 & 1.211 & 65.2 & 3.134 & 209 & .000\end{array}$ together.

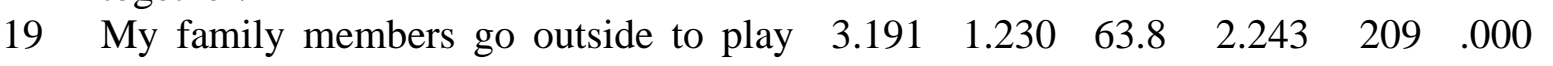
games together.

$\begin{array}{lllllll}20 & \text { My family members play indoor games } & 3.124 & 1.200 & 62.5 & 1.496 & 209\end{array}$ together.

21 My family members participate in $\begin{array}{lllllll}3.052 & 1.273 & 61.0 & 0.597 & 209 & .551\end{array}$ outdoor activities (fishing, boating, hiking, camping, etc.)

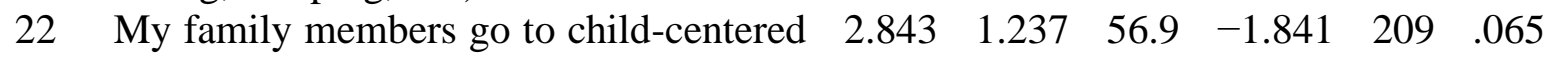
places together.

$\begin{array}{llllllll}23 & \text { My family members read books together. } & 2.533 & 1.137 & 50.7 & -5.947 & 209 & .000\end{array}$ $\begin{array}{lllllll}\text { Mean Quality Time Spent with Family } & 3.535 & 0.775 & 70.7 & 10.003 & 209 & .000\end{array}$

* On a 5-point scale, where $1=$ never $(1-20 \%), 2$ rarely $(21-40 \%), 3=$ sometimes $(41-60 \%), 4=$ often $(61-$ $80 \%)$, and $5=$ always $(81-100 \%)$.

$* *$ Test value $=3$

\section{Hypothesis Testing}

\section{Correlation Analysis}

Bivariate correlation was used to determine the significance of the relationships among variables. The variables are perception towards social media, attitude towards social media, behavior towards social media, and quality time spent with family. The results show that all of the variables tested generated positive and significant relationships (Table 10). The magnitudes for the strength of the relationships between the quality time spent with family and perception, attitude, and behavior were found to be weak.

Specifically, the relationship between perception towards social media and the quality time spent with family was weak but significant $(r=.268, \rho=.000)$. Hence, H1 was accepted. The relationship between attitude towards social media and the quality time spent with family showed a weak positive and significant value $(r=.266, \rho=.018)$. Hence, H2 was accepted. There was also a weak positive relationship between behavior towards social media and the quality time spent with family and it was significant $(r=.272, \rho=.000)$. Thus, H3 was Copyright $\odot$ GLOBAL ACADEMIC EXCELLENCE (M) SDN BHD - All rights reserved 
accepted. Therefore, perception, attitude, and behavior influenced the quality time spent with family. Therefore, all of the hypotheses are supported, and the fourth research objective is achieved.

The results indicate that students who use social media do spend quality time with their family. It shows that the time displacement theory, to some extent, does support quality time with family because of the use of social media for family communication. Probably, social media usage displaces other activities but hopefully not their study time. Otherwise, the students may not be able to perform well in their studies if they are deprived of their study time. Regardless, the results indicate that social media usage does encourage the quality time spent with family.

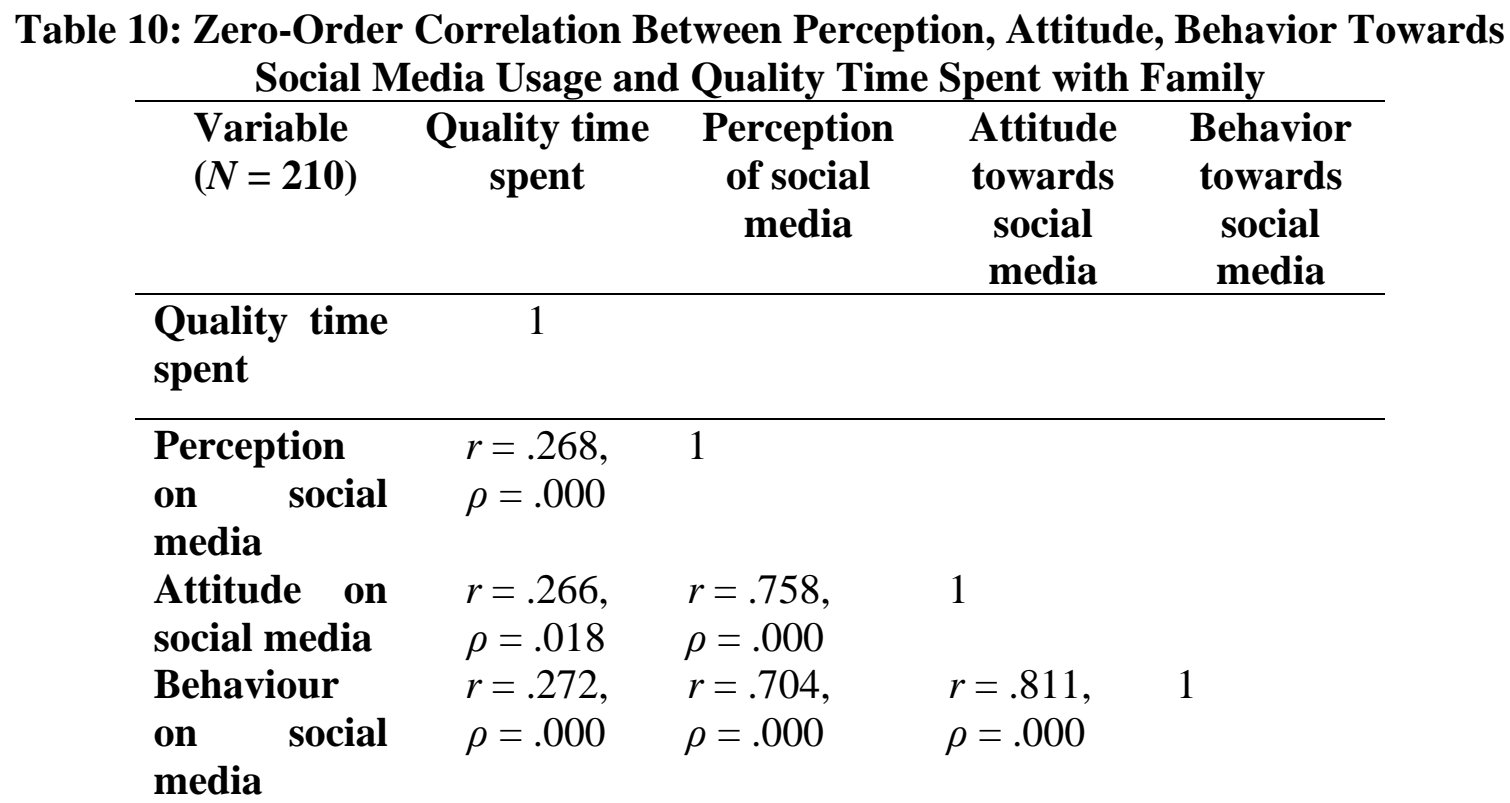

\section{Discussion}

The social media usage in this study has proven that students own and prefer to use smartphones and laptops the most to access their social media. This result is in line with Siew et al. (2017), which stated that the majority of students use smartphones and laptops to fulfil their needs such as accessing their social media. Also, the result indicates that IIUM students have a high level of usage and exposure towards social media, which is congruent with the finding by Subrahmanyam et al., (2004) that over 80 percent of students and youths around the world are exposed to and spend a lot of their time on the Internet and social media and they are among the first to face issues associated with excessive usage of social media.

Besides, this study also found that students spend more than half an hour per day on social media, which supports Kushairi's (2019) discovery that Malaysians spend an average of 2.8 hours a day on social media. Other studies also indicated that the majority of students access their social media every day (Aghaee, 2010) to fulfill their personal, communication, and interaction needs. In addition, the majority of the students rated social media as 'important' and 'very important' in family communication, which supports Watt's (2016) findings that social media usage among family members is important in maintaining the social connection and bonding among family members. 


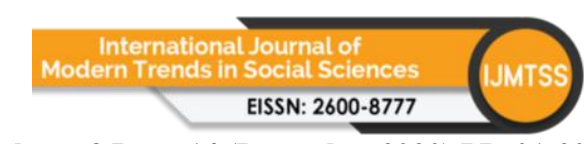

Volume 3 Issue 14 (December 2020) PP. 01-20

DOI 10.35631/IJMTSS.314001

The findings of this study show the existence of a relationship between each of perception, attitude, and behavior towards social media usage with the quality time spent with the family. The findings imply that students use social media to spend quality time with their family to a certain extent. Besides, the findings show that social media displaced some of their quality time with family for other activities. The result for perception towards social media usage and quality time spent with family coincides with Coyne et al. (2014), which found that family members have a positive perception towards social media usage in family communication as it allows them to remain in contact, spending time together to communicate.

Besides, the study's result for the attitude towards social media usage and quality time spent with family supports the findings of Abraham (2020) that students agreed that the attitude of adolescents towards social media helps to sustain their relationships with family members, especially among people who are unable to meet face-to-face. Similarly, Zhou et al. (2017) concluded that social media helps adolescents to remain close to their family members and peers. The finding of the behavior towards social media usage and quality time spent with family is in line with the findings of Pew Research Center's Internet and American Life Project (2008) that the behavior in using the Internet and social media helped families to balance their modern life by allowing them to stay in touch and spend quality time with family members when they were separated.

Thus, the theory of time displacement is supported as the correlations among the variables are weak, indicating that social media has displaced some of the quality time that students should spend with their family.

\section{Conclusion}

From a total of 210 students, the majority of them are females compared to males. They came from different backgrounds and levels of study. The results indicate that IIUM students have high exposure to social media use. There is also a high level of perception, attitude, and behavior towards social media usage and also the quality time spent with family.

The quality time spent with family has a positive and weak relationship with the perception, attitude, and behavior towards social media usage. All the hypotheses of this study are supported. Thus, to some extent perception, attitude, and behavior impose certain impacts and influences on the quality time spent with family. Therefore, the findings of this study support the theory used, that is, the time displacement theory. In addition, this study highlights the influence of social media usage on the quality time spent with family as people tend to spend more time on social media nowadays.

\section{Limitations of the Study}

Several problems were encountered when conducting the research. Since the study was conducted during the COVID-19 pandemic and most of the students had returned to their hometown due to the Movement Control Order (MCO), it was hard and difficult to find respondents in the campus. Data could only be collected through an online platform by distributing the questionnaire using Google Form through WhatsApp, Facebook, Messenger, and Telegram. The students' response was at their convenience. Thus, collecting the data was quite challenging as some of the respondents were not able to respond to the questionnaire given to them through the online platform due to a weak Internet connection. 


\section{Suggestions for Future Research}

It is suggested that future studies use a qualitative research design, for example, the in-depth interview method with the students to understand their experiences on the influence of their social media usage on the quality time spent with their family. This method helps to obtain rich data. The social presence theory (Short, Williams, \& Christie, 1976) can also be tested in future research as this theory can help in gaining an understanding of how students and their family members interact socially on an online platform. This theory helps to explain how family members interact on social media and how social media helps to influence them to have warm and personal relationships with other family members in spending quality time together. Similar studies should be conducted on international students, expatriates, and family members who stay apart.

\section{Biodata}

Siti Hajar Binti Mohd Badrol is a Master student at the Department of Communication in IIUM. She graduated with a Bachelor's Degree in Human Sciences (Language) specializing in Arabic Language and Literature from IIUM. Her research interests are Social Media and Family Communication.

Saodah Wok is a Professor at the Department of Communication, IIUM. She obtained her Ph.D. from University of Wisconsin-Madison, USA in Mass Communication and specializing in Organizational Communication. Her research interests are in Organizational Communication, Social Media, Women Studies, Health Communication, and Family Communication.

\section{References}

Abraham, B. (2020). The attitude of adolescent towards social media. International Journal of Advanced Research, 8, 443-453. http://dx.doi.org/10.21474/IJAR01/10480

Anderson, M., \& Jiang, J. (2020, May 30). Teens' social media habits and experiences. Retrieved July 11, 2020, from https://www.pewresearch.org/internet/2018/11/28/teenssocial-media-habits-and-experiences/

Aghaee, N. M. (2010). Social media usage in academia: Campus students perceptions of how using social media supports educational learning (Master's thesis, Uppsala Universitet, 2010) (pp. 1-39). Sweden: Uppsala Universitet.

Bernama. (2019, May 3). Social media main mode of communication says chief statistician. The Star. Retrieved from https://www.thestar.com.my/news/nation/2019/05/03/social-media-main-mode-ofcommunication-says-chief-statistician

Boyd, D. M., \& Ellison, N. B. (2008). Social network sites: Definition, history, and scholarship. Journal of Computer-Mediated Communication, 13, 210-230.

Christensen, P. H. (2002). Why more "quality time" is not on the top of children's list: The "qualities of time" for children. Children \& Society, 16, $77-88$. https://doi.org/10.1002/chi.709

Coyne, S. M., Padilla-Walker, L. M., Fraser, A. M., Fellows, K., \& Day, R. D. (2014). Media time = family time. Journal of Adolescent Research, 29(5), 663-688. https://doi.org/10.1177/0743558414538316

Daly, Kerry J. (2001). Deconstructing family time: From ideology to lived experience. Journal of Marriage and Family, 63(2), 283-294.

Eagly, A. H., \& Chaiken, S. (1993). The psychology of attitudes. Washington, DC: Harcourt Brace Jovanovich College Publishers. 
Edge, W. (2017). Nursing professionalism: Impact of social media use among nursing students. Journal of Healthcare Communications, 2(3), 1-3.

Ellington, A. S. (2011). The role of family time on a young child's overall development (Master's thesis). Tuscaloosa, Alabama: School of the University of Alabama.

Huisman S., Edwards A., \& Catapano S. (2012). The impact of technology on families International Journal Educational Psychology, 2(1), 44-62.

Kenton, W. (2019, May 6). Population definition. Retrieved from https://www.investopedia.com/terms/p/population.asp

Kushairi, A. (2017, May 3). Mind your manners online. New Straits Time. Retrieved from https://www.nst.com.my/opinion/columnists/2017/05/235979/mind-your-manners online

Lanigan, J. D. (2009). A Socio-technological model for family research and intervention: How information and communication technologies affect family life. Marriage \& Family Review, 45(6-8), 587-609. https://doi.org/10.1080/01494920903224194

Lavrakas, P. J. (2008). Encyclopedia of survey research methods (Vols. 1-10). Thousand Oaks, CA: Sage Publications, Inc. https://doi.org/10.4135/9781412963947

Lucas Jr, H. C., Agarwal, R., Clemons, E. K., El Sawy, O. A., \& Weber, B. W. (2013). Impactful research on transformational information technology: An opportunity to inform new audiences. MIS Quarterly, 37(2), 371-382.

McCombs, N. (1992). The relative constancy approach to consumer spending for media. Journal of Media Economics, 5(2), 42-53.

Müller, J. (2020, July 13). Malaysia: Social media penetration 2020. Retrieved March 20, 2020, from https://www.statista.com/statistics/883712/malaysia-social-media-penetration/

Neuman, S. (1991). Literacy in the television age. Norwood, NJ: Ablex Publishing.

Perrin, A. (2020, May 30). Social media usage: 2005-2015. Retrieved from https://www.pewresearch.org/internet/2015/10/08/social-networking-usage-2005 2015/

Pew Research Center. (2008, October 19). Families and technology. Retrieved from https://www.pewresearch.org/internet/dataset/january-2008-families/

Qi, E., Shen J., \& Dou, R. (Eds.). (2013). The 19th international conference on industrial engineering and engineering management. Berlin: Springer Science \& Business Media.

Rosly, F. (2018, August 13). Kerajaan kaji sekat remaja akses internet selepas 12 malam. Berita Harian. Retrieved from https://www.bharian.com.my/berita/nasional/Neuman

Subrahmanyam, K., Greenfield, P. M., \& Tynes, B. (2004). Constructing sexuality and identity in an online teen chat room. Journal of Applied Developmental Psychology, 25(6), 651666. https://doi.org/10.1016/j.appdev.2004.09.007

Watt, J. B. (2016). Effects of social media use on family relationships. (Master's thesis), California State University, Northridge.

Zhou, L., Zhang, D., Yang, C. C., \& Wang, Y. (2017). Harnessing social media for health information management. Electron Commer Res Appl, 27, 139-151. https://doi.org/10.1016/j.elerap.2017.12.003 